\title{
Cryolipolysis for noninvasive body contouring: clinical efficacy and patient satisfaction
}

This article was published in the following Dove Press journal:

Clinical, Cosmetic and Investigational Dermatology

26 June 2014

Number of times this article has been viewed

\author{
Nils Krueger' \\ Sophia V Mai \\ Stefanie Luebberding ${ }^{\prime}$ \\ Neil S Sadick ${ }^{3}$ \\ 'Rosenpark Research, Darmstadt, \\ Germany; ${ }^{2}$ Department of \\ Dermatology, Louisiana State \\ University, New Orleans, LA, \\ ${ }^{3}$ Department of Dermatology, Weill \\ Cornell Medical College, New York, \\ NY, USA
}

\begin{abstract}
In recent years, a number of modalities have become available for the noninvasive reduction of adipose tissue, including cryolipolysis, radiofrequency, low-level laser, and highintensity focused ultrasound. Each technology employs a different mechanism of action to cause apoptosis or necrosis of the targeted adipocytes. Among these technologies, cryolipolysis has not only been commercially available for the longest time, but has also been best researched including in vitro and animal models and randomized controlled clinical trials in humans. The principle behind cryolipolysis exploits the premise that adipocytes are more susceptible to cooling than other skin cells. The precise application of cold temperatures triggers apoptosis of the adipocytes, which invokes an inflammatory response and leads to slow digestion by surrounding macrophages. In clinical studies, cryolipolysis was shown to reduce subcutaneous fat at the treatment site by up to $25 \%$ after one treatment. Improvements were seen in $86 \%$ of treated subjects. At $73 \%$, the patient satisfaction rate is higher than with other technologies used for noninvasive lipolysis. Cryolipolysis has been proven to be a very safe method for body contouring, and is accomplished with only minimal discomfort. Expected side effects are temporary erythema, bruising, and transient numbness that usually resolve within 14 days after treatment. With a prevalence of $0.1 \%$, the most common complaint is late-onset pain, occurring 2 weeks post-procedure, which resolves without intervention. Although no procedure has been accepted as the gold standard for noninvasive body contouring as yet, cryolipolysis is considered to be both safe and efficient with a high patient satisfaction rate.
\end{abstract}

Keywords: cryolipolysis, nonsurgical fat reduction, body contouring, patient satisfaction, patient safety

\section{Introduction}

In 2012, it was estimated that over 10 million cosmetic procedures were performed in the USA, with total expenditures reaching 11 billion dollars. This represents a $250 \%$ increase in demand for both surgical and minimally invasive cosmetic procedures over the last two decades. However, despite our culture's obsession with attaining media-perpetuated standards of beauty and ideal body shapes, the number of cosmetic surgical procedures has declined by $16 \%$ since 2000 , while the number of minimally invasive procedures has increased by $137 \%$ simultaneously. ${ }^{1}$ These procedures are often called "lunch time procedures" because they come with minimal down times and can be completed in less than 2 hours. Nowadays, both men and women are looking for quick, affordable, and safe minimally invasive fixes to maintain their youthful appearance and increase their attractiveness. These procedures are not limited to the face, and can also include treatment of body contour and shape. For decades, liposuction was
Correspondence: Nils Krueger

Rosenpark Research,

Wilhelminenstrasse 13,

64283 Darmstadt, Germany

Tel +496I5I I5988385

Email nils.krueger@rosenparkresearch.de 
the only accepted procedure for body contouring; it has now been receiving more and more competition from noninvasive approaches that involve no anesthesia, operating room time, or surgical incisions to the skin. While the results of these new technologies are less dramatic and immediate, they come without the level of risk and side effects associated with surgical procedures.

\section{Body contouring techniques}

A number of newly designed modalities have become available to the consumer recently, each employing a different mechanism of action to reduce the appearance of adipose tissue (Table 1). One such method uses high-intensity focused ultrasound to deliver focused acoustic energy at specific depths in subcutaneous tissue, and has been cleared by the US Food and Drug Administration (FDA). The combination of a mechanical effect, that disrupts the cell membranes immediately, and a thermal mechanism, that destroys adipocytes at temperatures above $58^{\circ} \mathrm{C}$, causes coagulative necrosis within a small targeted area while the surrounding tissue remains mostly unaffected. ${ }^{2}$ Studies have shown evidence of fat necrosis ${ }^{3}$ and an average reduction in waist circumference of more than $2 \mathrm{~cm} 12$ weeks after a single treatment. ${ }^{4}$

Other players in body contouring include radiofrequency devices. While this technique also causes thermal injury to targeted tissue layers, it does so using electrical energy. Radiofrequency devices have traditionally been used for tightening of skin laxity and rhytides, as the thermal damage that ensues results in contraction of collagen and remodeling. ${ }^{5}$ However, a clinical study by Franco et $\mathrm{al}^{6}$ shows that radiofrequency devices can be used to selectively heat subcutaneous

Table I Comparison of technologies for fat reduction

\begin{tabular}{|c|c|c|c|c|}
\hline Technology & $\begin{array}{l}\text { Mechanism } \\
\text { of action }\end{array}$ & $\begin{array}{l}\text { Pain } \\
\text { level }\end{array}$ & Side effects & $\begin{array}{l}\text { Treatments } \\
\text { needed }(n)\end{array}$ \\
\hline $\begin{array}{l}\text { High-intensity } \\
\text { focused } \\
\text { ultrasound }\end{array}$ & Necrosis & High & $\begin{array}{l}\text { Massive } \\
\text { bruising and } \\
\text { tenderness up } \\
\text { to } 2 \text { weeks }\end{array}$ & $\mathrm{I}-2$ \\
\hline $\begin{array}{l}\text { Unipolar } \\
\text { radiofrequency }\end{array}$ & Apoptosis & Medium & $\begin{array}{l}\text { Redness and } \\
\text { tenderness } \\
\text { for I-3 days }\end{array}$ & $2-3$ \\
\hline $\begin{array}{l}\text { Low-level } \\
\text { laser therapy }\end{array}$ & Apoptosis & None & None & 6 \\
\hline $\begin{array}{l}\text { Acoustic } \\
\text { wave therapy }\end{array}$ & Apoptosis & None & None & 8 \\
\hline Cryolipolysis & Apoptosis & Low & $\begin{array}{l}\text { Numbness and } \\
\text { bruising for up } \\
\text { to } 7 \text { days }\end{array}$ & $\mathrm{I}-2$ \\
\hline
\end{tabular}

adipose tissue and induce lethal thermal damage to adipose tissue while sparing the overlying and underlying tissues. Thermal exposures to $43^{\circ} \mathrm{C}-45^{\circ} \mathrm{C}$ over several minutes may result in a delayed adipocyte death response. This may have a role in decreasing overall waist circumference and fat removal as well. ${ }^{7}$ Uniform heating of subcutaneous tissue at sustained therapeutic temperatures has been shown to trigger apoptosis of cells. ${ }^{8}$ A decrease in fat volume is supposed to be seen 3-8 weeks after treatment.

Low-level laser therapy is a unique modality that is not based on thermal tissue damage. Its efficacy is still under investigation; however, one of the proposed mechanisms of action is based on the concept of producing transient pores in adipocytes, allowing lipids to leak out. ${ }^{9,10}$ Another proposed noninvasive means of reducing localized fat accumulation is acoustic wave therapy. Mechanical stimuli from application of these short pulsed waves are thought to activate new collagen growth, stimulate angiogenesis around fat cells, and activate lipases, resulting in tightening and improved appearance of cellulite. ${ }^{11}$

\section{Cryolipolysis and its mechanism of action}

Cryolipolysis is a completely different modality from the techniques discussed so far. The principle behind this technology exploits the premise that adipocytes are more susceptible to cooling than other skin cells.

Precise application of cold temperatures triggers the death of adipocytes that are subsequently engulfed and digested by macrophages. ${ }^{12,13}$ No changes in subcutaneous fat are noticeable immediately after treatment. An inflammatory process stimulated by apoptosis of adipocytes, as reflected by an influx of inflammatory cells, can be seen within 3 days after treatment and peaks at approximately 14 days thereafter as the adipocytes become surrounded by histiocytes, neutrophils, lymphocytes, and other mononuclear cells. At 14-30 days after treatment, macrophages and other phagocytes surround, envelope, and digest the lipid cells as part of the body's natural response to injury. Four weeks after treatment, the inflammation lessens and the adipocyte volume is decreased. Two to 3 months after treatment, the interlobular septa are distinctly thickened and the inflammatory process further decreases. By this time, the fat volume in the treated area is apparently decreased and the septae account for the majority of the tissue volume. ${ }^{14,15}$

In 2010, the FDA cleared a cryolipolytic device (CoolSculpting $^{\circledR}$; ZELTIQ Aesthetics, Inc., Pleasanton, CA, USA) for reduction of flank and abdominal fat. In April 2014, 
the FDA also cleared this system for the treatment of subcutaneous fat in the thighs (Figure 1).${ }^{16}$ One part of the device is a cup-shaped applicator with two cooling panels that is applied to the treatment area. The tissue is drawn into the handpiece under moderate vacuum and the selected temperature is modulated by thermoelectric elements and controlled by sensors that monitor the heat flux out of the tissue. Each area is treated for approximately 45 minutes and should be massaged for 2 minutes upon completion to improve the clinical outcome. The patient is then discharged home and is free to resume normal activities immediately after treatment. ${ }^{17}$ The number of treatment cycles needed depends on the treatment area. While good results at the flanks can usually be achieved with only one treatment, the back and the inner and outer thighs often require more than two treatments. ${ }^{18}$ Repeated treatment sessions should be spaced 8 weeks apart to allow the inflammatory process to resolve. ${ }^{15}$

\section{Clinical efficacy and safety of cryolipolysis}

The clinical efficacy and safety of cryolipolysis has been studied in both human and animal models. In two separate studies, animal models demonstrated a reduction of up to $1 \mathrm{~cm}$ or $40 \%$ of the total fat layer thickness after a single exposure without harming the overlying skin. ${ }^{12,13}$ Manstein et al found lipid-laden mononuclear inflammatory cells and local thickening of fibrous septae at 2 weeks post-procedure, implicating apoptosis and phagocytosis as contributing factors in the mode of action. ${ }^{12}$ Evaluation of lipids over a 3-month period following treatment showed normal cholesterol and triglyceride levels. ${ }^{13}$
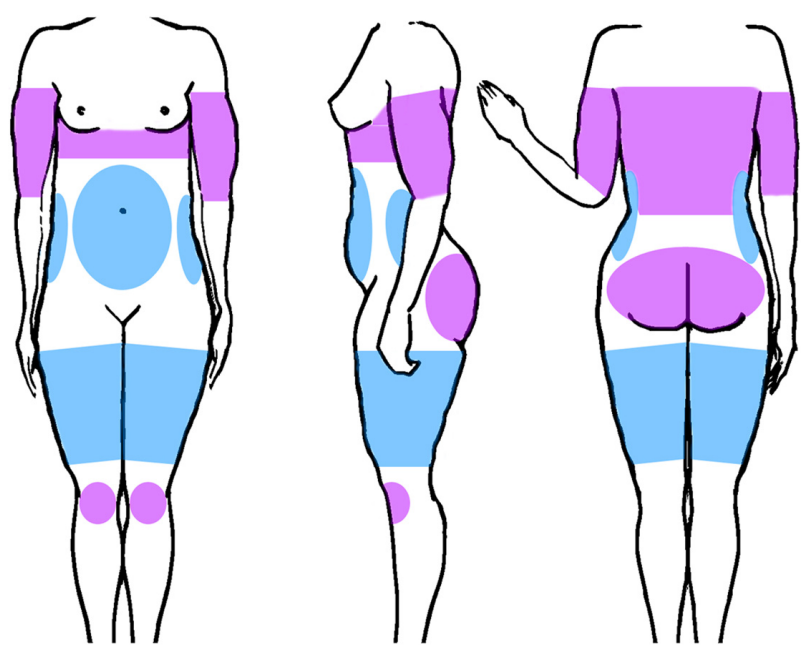

Figure I Indications cleared by the US Food and Drug Administration (blue) and off-label indications (pink) for cryolipolysis as mentioned in peer-reviewed publications.
Several studies in humans have shown comparable results. One study published in 2009 involving ten subjects reported a $20.4 \%$ and $25.5 \%$ reduction in the fat layer 2 months and 6 months after treatment, respectively. ${ }^{19}$ More recently, a retrospective multicenter study using patient surveys, photographic documentation, and caliper measurements, was published by Dierickx et al. ${ }^{20}$ These investigators reported that $86 \%$ of 518 subjects showed improvement. The body sites at which cryolipolysis was most effective were the abdomen, back, and flank. Patients completed a satisfaction questionnaire, with $73 \%$ reporting being satisfied and $82 \%$ being prepared to recommend cryolipolysis to a friend. The majority described minimal to tolerable discomfort during the procedure. Eighty-nine percent of respondents reported a positive perception of the treatment duration. In a report on the clinical and commercial experience with cryolipolysis in a private plastic surgery practice, only six of 528 patients were dissatisfied with the clinical outcome; four of these six patients were satisfied when treated a second time. ${ }^{18}$ A study by Garibyan et al used a three-dimensional camera to evaluate the amount of fat loss after cryolipolysis. Mean fat loss between baseline and the 2-month follow-up visit was $56.2 \pm 25.6 \mathrm{cc}$ on the treated side and $16.6 \pm 17.6 \mathrm{cc}$ on the control side $(P<0.0001)$. Two months post-treatment, the mean difference in fat loss between the treated and untreated sides was $39.6 \mathrm{cc} .{ }^{21}$ In an uncontrolled study by Ferraro et al, cryolipolysis was combined with acoustic waves to achieve possible synergistic effects. These authors reported significant reductions of up to $6.7 \mathrm{~cm}$ in circumference and up to $4.5 \mathrm{~cm}$ in thickness of the fat layer 12 weeks after 3-4 treatments. ${ }^{22}$ However, it should be pointed out that body contouring studies are difficult to perform because natural variability is high and the reproducibility of many measurements is low.

The long-term duration of effect of cryolipolysis has not been evaluated as yet. Only one small case study of two subjects who were treated unilaterally on one flank and followed photographically for up to 5 years post-procedure has been published. In this study, fat reduction was found to be durable despite fluctuations in body weight. ${ }^{23}$ Although little to nothing is known about the durability of fat loss induced by selective cryolysis, there is no evidence that the fat lost after cold exposure could regenerate.

With regard to the safety profile, several publications including two systematic literature reviews have failed to identify any significant adverse events that could be attributed to cryolipolysis, including scarring, ulceration, or disfigurement. Although cold temperatures are known to 
induce subcutaneous panniculitis, no cases of nodule formation have been reported. ${ }^{12-23}$ Expected side effects are temporary erythema, bruising, and transient numbness that usually resolve within 14 days after treatment. ${ }^{13}$ With more than 850,000 procedures performed worldwide, only 850 adverse events have been reported. The most common complaint is late-onset pain, occurring 2 weeks post-procedure, that resolves without intervention. Paradoxical adipocyte hyperplasia, a condition where additional fat grows at the treatment site and occurs approximately 6 months postoperatively, has been reported in 33 cases. $^{24}$ The pathogenesis of this phenomenon is unknown, but several hypothesized mechanisms are under discussion. Possible treatments rely on liposuction or abdominoplasty, because spontaneous resolution has not been reported as yet. Sensory alteration was investigated by Coleman et al in nine subjects by clinical neurological examination and biopsy for nerve staining. ${ }^{19}$ Six of the nine patients had a transient reduction in sensation, which returned to normal after a mean of 3.6 weeks. There were no neural changes on the biopsies. Potential changes in lipid levels after treatment were assessed in the two studies without any significant findings. ${ }^{14-25}$ Further, no notable changes in liver function were found in 40 patients followed for 12 weeks after cryolipolysis. ${ }^{25}$

\section{Discussion}

All nonsurgical procedures for body sculpting rest on the principle of either inducing fat cell necrosis or apoptosis in order to achieve a discernible and quantifiable result. A variety of modalities can be used to achieve this goal, including laser light, radiofrequency, acoustic waves, coldness, or chemicals. They differ from each other not only by their mechanism of action, but also in response rate, side effects, level of discomfort/pain, and the number of treatments needed. Although no procedure has been accepted as the gold standard as yet, cryolipolysis is considered to be both safe and effective, with a high patient satisfaction rate of up to $73 \%$ after one treatment. ${ }^{20}$ This rate is comparable with that of high-intensity focused ultrasound and acoustic wave therapy (62.3\% and 64\%, respectively). However, these modalities are associated with either a higher rate of adverse events and pain or a high number of up to eight treatments necessary to achieve the desired effect. ${ }^{4-11}$ Studies assessing patient satisfaction and efficacy with radiofrequency for fat reduction have not been published as yet. To the authors' best knowledge, no studies assessing the influence of noninvasive body contouring procedures on quality of life have been reported at the time of writing. However, studies show that surgical body contouring as well as weight loss in general have a positive influence on quality of life..$^{26,27}$

Cryolipolysis is safe for all skin types, with no reported pigmentary changes, and is safe for repeated application. ${ }^{18}$ The best candidates are those within their ideal weight range and those who engage in regular exercise, eat a healthy diet, have noticeable fat bulges on the trunk, are realistic in their expectations, and are willing to maintain the results of cryolipolysis with a healthy, active lifestyle. However, there is a lack of substantial research, with current knowledge based only on uncontrolled case studies and retrospective practice reviews. No head-to-head studies evaluating noninvasive body contouring devices have been conducted as yet. More randomized, controlled, double-blind studies with a sufficient number of subjects and objective measurements with high reproducibility are needed to evaluate the short-term and long-term efficacy and side effects of cryolipolysis. Further research should be directed towards identifying more ideal settings and maintenance programs.

\section{Disclosure}

The authors report no conflicts of interest in this work.

\section{References}

1. The American Society for Aesthetic Plastic Surgery. 2012 Plastic Surgery Statistics Report Annual Statistics. Available from: http://www. plasticsurgery.org/news/plastic-surgery-statistics/2012-plastic-surgerystatistics.html. Accessed May 17, 2014.

2. Fatemi A, Kane MAC. High-intensity focused ultrasound effectively reduces waist circumference by ablating adipose tissue from the abdomen and flanks: a retrospective case series. Aesthetic Plast Surg. 2010;34(5): 577-582.

3. Shalom A, Wiser I, Brawer S, Azhari H. Safety and tolerability of a focused ultrasound device for treatment of adipose tissue in subjects undergoing abdominoplasty: a placebo-control pilot study. Dermatol Surg. 2013;39(5):744-751.

4. Jewell ML, Baxter RA, Cox SE, et al. Randomized sham-controlled trial to evaluate the safety and effectiveness of a high-intensity focused ultrasound device for noninvasive body sculpting. Plast Reconstr Surg. 2011;128(1):253-262.

5. Zelickson BD, Kist D, Bernstein E, et al. Histological and ultrastructural evaluation of the effects of a radiofrequency-based nonablative dermal remodeling device: a pilot study. Arch Dermatol. 2004;140(2): 204-209.

6. Franco W, Kothare A, Ronan SJ, Grekin RC, McCalmont TH. Hyperthermic injury to adipocyte cells by selective heating of subcutaneous fat with a novel radiofrequency device: feasibility studies. Lasers Surg Med. 2010;42(5):361-370.

7. Manuskiatti W, Wachirakaphan C, Lektrakul N, Varothai S. Circumference reduction and cellulite treatment with a TriPollar radiofrequency device: a pilot study. J Eur Acad Dermatol Venereol. 2009;23(7):820-827.

8. Franco W, Kothare A, Goldberg DJ. Controlled volumetric heating of subcutaneous adipose tissue using a novel radiofrequency technology. Lasers Surg Med. 2009;41(10):745-750.

9. McRae E, Boris J. Independent evaluation of low-level laser therapy at $635 \mathrm{~nm}$ for non-invasive body contouring of the waist, hips, and thighs. Lasers Surg Med. 2013;45(1):1-7. 
10. Avci P, Nyame TT, Gupta GK, Sadasivam M, Hamblin MR. Low-level laser therapy for fat layer reduction: a comprehensive review. Lasers Surg Med. 2013;45(6):349-357.

11. Adatto MA, Adatto-Neilson R, Novak P, Krotz A, Haller G. Body shaping with acoustic wave therapy AWT $\left({ }^{\circledR}\right) / \operatorname{EPAT}\left({ }^{\circledR}\right)$ : randomized, controlled study on 14 subjects. J Cosmet Laser Ther. 2011;13(6): 291-296.

12. Manstein D, Laubach H, Watanabe K, Farinelli W, Zurakowski D, Anderson RR. Selective cryolysis: a novel method of non-invasive fat removal. Lasers Surg Med. 2008;40(9):595-604.

13. Zelickson B, Egbert BM, Preciado J, et al. Cryolipolysis for noninvasive fat cell destruction: initial results from a pig model. Dermatol Surg. 2009;35(10):1462-1470.

14. Nelson AA, Wasserman D, Avram MM. Cryolipolysis for reduction of excess adipose tissue. Semin Cutan Med Surg. 2009;28(4):244-249.

15. Avram MM, Harry RS. Cryolipolysis for subcutaneous fat layer reduction. Lasers Surg Med. 2009;41(10):703-708.

16. US Food and Drug Administration. 510(k) clearance K133212. 2014. Available from: http://www.accessdata.fda.gov/cdrh_docs/pdf13/ K133212.pdf. Accessed May 17, 2014.

17. Jalian HR, Avram MM. Cryolipolysis: a historical perspective and current clinical practice. Semin Cutan Med Surg. 2013;32(1):31-34.

18. Stevens WG, Pietrzak LK, Spring MA. Broad overview of a clinical and commercial experience with CoolSculpting. Aesthetic Surg J. 2013;33(6):835-846.

19. Coleman SR, Sachdeva K, Egbert BM, Preciado J, Allison J. Clinical efficacy of noninvasive cryolipolysis and its effects on peripheral nerves. Aesthetic Plast Surg. 2009;33(4):482-448.
20. Dierickx CC, Mazer JM, Sand M, Koenig S, Arigon V. Safety, tolerance, and patient satisfaction with noninvasive cryolipolysis. Dermatol Surg. 2013;39(8):1209-1216.

21. Garibyan L, Sipprell WH, Jalian HR, Sakamoto FH, Avram M, Anderson RR. Three-dimensional volumetric quantification of fat loss following cryolipolysis. Lasers Surg Med. 2014;46(2):75-80.

22. Ferraro GA, De Francesco F, Cataldo C, Rossano F, Nicoletti G, D'Andrea F. Synergistic effects of cryolipolysis and shock waves for noninvasive body contouring. Aesthetic Plast Surg. 2012;36(3): 666-679.

23. Bernstein EF. Longitudinal evaluation of cryolipolysis efficacy: two case studies. J Cosmet Dermatol. 2013;12(2):149-152.

24. Jalian HR, Avram MM, Garibyan L, Mihm MC, Anderson RR. Paradoxical adipose hyperplasia after cryolipolysis. JAMA Dermatol. 2014;150(3):317-319.

25. Klein KB, Zelickson B, Riopelle JG, et al. Non-invasive cryolipolysis for subcutaneous fat reduction does not affect serum lipid levels or liver function tests. Lasers Surg Med. 2009;41(10):785-790.

26. Smeets R, Noah EM, Seiferth NY, et al. Bioelectric impedance analysis and quality of life after body-contouring procedures in plastic surgery. J Plast Reconstr Aesthet Surg. 2009;62(7):940-945.

27. Milder IEJ, de Hollander EL, Picavet HS, Verschuren WM, de Groot LC, Bemelmans WJ. Changes in weight and health-related quality of life. The Doetinchem Cohort Study. J Epidemiol Community Health. 2014;68(5):471-477.
Clinical, Cosmetic and Investigational Dermatology

\section{Publish your work in this journal}

Clinical, Cosmetic and Investigational Dermatology is an international, peer-reviewed, open access, online journal that focuses on the latest clinical and experimental research in all aspects of skin disease and cosmetic interventions. All areas of dermatology will be covered; contributions will be welcomed from all clinicians and

\section{Dovepress}

basic science researchers globally. This journal is indexed on CAS The manuscript management system is completely online and includes a very quick and fair peer-review system, which is all easy to use. Visit http://www.dovepress.com/testimonials.php to read real quotes from published authors. 